\title{
Suárez y el advenimiento del concepto de ente 1
}

\section{Suárez and the advent of the concept of being}

\author{
Pierre AuBENQue
}

Recibido: 20/12/2013

Aceptado: 12/11/2014

\section{Resumen}

En este trabajo se intenta explicar aquello que Heidegger dijo de Suárez en Ser y Tiempo, es decir, se intenta explicar qué papel juega Suárez en la Historia de la Metafísica, particularmente en cómo lo que en origen era un problema pasa a tornarse en una disciplina: la Ontología; y cómo también las consecuencias, que se derivan de la posición de Suárez y especificamente su forma de entender el conceptus entis, marcan el futuro de la Metafísica moderna.

Palabras clave: Suárez, Aristóteles, Wolff, Kant, Concepto de ser, Historia de la Metafísica.

\section{Abstract}

This work's purpose is to explain those words that Heidegger said about Suárez in Being and Time, i.e., to explain what is the importance of Suárez in the History of Metaphysics, specially on how something that was in its origin a problem became a discipline: the ontology; and also how the consequences that came from Suárez, and particularly how he understand the conceptus entis, mark the future of the Metaphysics of the Modernity.

Keywords: Suárez, Aristotle, Wolff, Kant, Concept of being, History of Metaphysics.

\footnotetext{
${ }^{1}$ Este artículo ha sido previamente publicado en francés con el título: Aubenque, P. «Suárez et l'avènement du concept d'être.» Cardoso, A., Martins, A.M., Ribeiro Dos Santos, L. (Eds.) Francisco Suárez 1548-1617, Ediçoes colibri / Centro de Filosofia da Universidade de Lisboa, Lisboa, 1999, páginas 11-20. Traducción del texto francés: Nicolás Silva Sepúlveda. [Nota traductor: Agradezco a Guillermo Fernández Vázquez por sus siempre pertinentes observaciones y correcciones.]
} 
En este año, donde celebramos a la vez el cuatrocientos y cincuenta aniversario del nacimiento de Francisco Suárez y el cuatrocientos aniversario de las Disputationes metaphysicae, yo querría intentar tomar la medida del acontecimiento que supuso esta publicación en la historia de la ontología e intentar precisar su sentido. En un texto a menudo citado del parágrafo sexto de Sein und Zeit, Heidegger subraya la importancia de Suárez para la transmisión de la ontología griega elaborada por la escolástica al moderno occidente: Suárez será aquel que, al momento mismo del aparente declinar de esta ontología, vuelve a dar en una suerte de in extremis la articulación interna y la fuerza que le permitirán inspirar subterráneamente la metafísica y la filosofía trascendental de los modernos y «determina todavía los fundamentos y los fines de la Lógica de Hegel»². Suárez será, pues, un factor de continuidad, aquel que asegura, en su posición histórica media entre la edad media y la modernidad, la permanencia de la estructura onto-teológica que, según Heidegger, determina el destino de la metafísica de acuerdo a una línea que va desde Parménides a Hegel y quizá incluso hasta Nietzsche.

Por otro lado, es evidente que esta transmisión no se da sin una alteración decisiva de estos conceptos e incluso de la problemática de la onto-teología tradicional. La innovación es disimulada por el mismo Suárez, que se reclama constantemente parte de los autores anteriores, particularmente de Santo Tomás; pero la innovación es real y, de hecho, manifestará su fuerza y su irreversibilidad en los efectos que producirá. Basta evocar aquí la profunda transformación de los conceptos ontológicos heredados de la tradición (como aquel de sustancia) que, en la estela de Suárez y sus discípulos, tornó inmediatamente posible las Meditaciones de Descartes o la Ética de Spinoza. J.-F. Courtine, que es uno de los artífices del renovado interés que constatamos hoy por la filosofía de Suárez, habló de una "inflexión suareziana"3. La inflexión excluye la linealidad, pero no la continuidad, en cierto sentido, incluso la presupone. Cuando en 1948 los jesuitas de Francia quisieron celebrar en su revista Archives de Philosophie el cuarto centenario de Suárez, titularon el fascículo que le estaba dedicado de la siguiente manera: Suárez (1548-1948). Modernidad tradicional de su filosofía. Este título, que es más profundo de lo que parece, no ha perdido, cincuenta años después, ni un ápice de su pertinencia.

Me gustaría, pues, intentar precisar aquí lo que a través de Suárez, pero también por él, pudo pasar de la tradición aristotélico-escolástica a la modernidad y ello a propósito de lo que constituye el concepto central o uno de los conceptos centrales de la metafísica, el concepto de ser, que es la cuestión de la segunda Disputatio: «De

\footnotetext{
2 Sein und zeit, p. 22. (Heidegger, M. Ser y tiempo; Rivera C., J.E. (trd.); Santiago de Chile: Editorial Universitaria, $4^{\circ}$ reimpresión, 2005 pág. 46).

3 Courtine, J.-F. «Différence ontologique et analogie de l'être. Le tournant suarézien», in Bulletin de la Société française de Philosohie, 83, n², 1989. Cf. id., Suarez et le système de la métaphysique, Paris, 1990.
} 
ratione essentiali seu conceptu entis». Podría parecer obvio que, si la metafísica es entendida como ciencia del ser en tanto que tal, su primer objetivo sea dilucidar el concepto que ella va a tratar. Pero el concepto de ser, si al menos hay uno, es decir, un concepto uno, no es un concepto como los otros, cuya existencia está suficientemente atestiguada por los objetos a los cuales se aplica. En el caso del ser, es necesario de entrada establecer que este concepto existe. Esto no es evidente, incluso si hay muchos individuos o situaciones que nosotros ordenamos bajo la denominación de entes. El que hablemos de ser no implica que haya un concepto uno de ser. De donde viene el título de la sección I y II: «utrum ens habeat unum conceptum».

Una duda fundamental había sido introducida bajo este punto por el mismo Aristóteles. Para él, el ser es una palabra que se dice en múltiples sentidos: ser por sí y ser por accidente, ser según las categorías, ser como verdadero, ser en acto y en potencia. Esta enumeración y, al interior de ella, la enumeración de los sentidos categoriales del ser constituyen un argumento muy fuerte contra la univocidad de un eventual concepto de ser. Un concepto no unívoco se analiza en el mejor de los casos, y después, por tanto, se disuelve, en una pluralidad de conceptos, dentro de los cuales alguno es unívoco. El concepto no unívoco no es, pues, un concepto en sí mismo. En el mismo sentido va la tesis de Aristóteles según la cual el ser no es un género: el ser denota realidades jerarquizadas (que comportan lo anterior y lo posterior), que la subsunción bajo un concepto común privaría de algunas características, probablemente las más pertinentes, que son las de los términos superiores de la serie. Entre lo más y lo menos, no hay en común más que lo menos, pero lo menos no permite concebir lo más.

Esta aporía es, se podría decir, la cruz de la metafísica desde su inicio. De hecho, se trata de una doble aporía, puesto que ella concierne, por un lado, la cuestión de saber si hay unidad o no de los sentidos categoriales del ser (problema de la unidad predicamental) y si hay unidad o no de los sentidos del ser aplicados a una jerarquía de entes (el problema de la unidad trascendental). De ahí retoma Suárez dos cuestiones clásicas: ¿Hay algo en común entre la sustancia, primera de las categorías, y las otras categorías, subsumibles bajo el predicable del accidente? ¿Y qué sería eso común? ¿Hay algo en común que merezca la denominación común "ser" entre Dios y la criatura, entre el ens infinitum et ens finitum? ¿Y qué sería eso común?

Los tipos de respuesta a estas dos cuestiones se ordenan en la tradición aristotélico-escolástica entre las dos posiciones extremas de la equivocidad y de la univocidad pura. La tesis de la equivocidad pura, que reduciría el ser a una palabra en la que no se reconoce otra unidad más que la nominal, está poco representada, si acaso puede serlo por Maimónides. La tesis de la univocidad es aquella que se atribuye a Duns Scoto. Entre las dos se sitúa la posición, hoy día finalmente reconocida por los intérpretes, del propio Aristóteles: el ser es un pros hen legomenon, es 
decir, un término cuyos múltiples sentidos no son reducibles a la unidad, pero mantienen entre ellos una unidad indirecta a partir del mero hecho de que se relacionan hacia (pros) un término único, al cual ellos están suspendidos o hacia el cual ellos convergen. Suspensión o convergencia: estas dos metáforas, aquella de la clave de bóveda y aquella del foco en el sentido óptico del término, se reencuentran la una y la otra en Aristóteles: ambas evocan una relación de dependencia no recíproca (el segundo término no existe sin el primero, pero no se deriva de él) o la idea de una visión común. Se habla en este último sentido de una unidad focal o de significación focal (focal meaning), expresión que tiende a suplantar hoy día con razón la noción de "analogía de atribución" por la que Santo Tomás había tratado de verter al latín el pros hen legomenon de Aristóteles.

La Edad Media, en efecto, denominó de una forma general analogía a lo que en Aristóteles era una unidad focal. Esta traducción constituía, en realidad, una alteración, en la medida en que el sentido matemático de la expresión - igualdad geométrica o proporción - introducía una suerte de conmensurabilidad entre términos o significaciones que en Aristóteles permanecerían irreductiblemente heterogéneas; estando esta misma conmensurabilidad fundada sobre la dependencia (entendida esta vez como derivación lógica) a un primer principio. Como Aristóteles dice una vez ${ }^{4}$ que la filosofía primera es también «universal (katholou) porque primera» es decir, ciencia universal del ser en tanto que ciencia de lo primero (que es Dios), se pudo nombrar a esta estructura "onto-teo-lógica"5 o más formalmente " katholouproto-lógica"'6.

$* * *$

¿Qué se da en Suárez?

Suárez distingue entre conceptus formalis y conceptus objectivus. ${ }^{7}$ El concepto formal es «el acto por el cual el intelecto concibe una cosa (res) o la noción común de esta cosa». El concepto objetivo es «la cosa misma o la razón (ratio) que es concebida o representada inmediatamente por el concepto formal», ratio que tiene aquí el sentido de noema o de esencia (de la cosa misma). Esta distinción es interesante, pero: ¿tiene un valor probatorio cuando se trata de establecer la existencia de un concepto? ¿Del hecho de que yo tengo un concepto formal de una cosa se sigue el que esta cosa sea o, como dijo Suárez, sea un concepto objetivo?

\footnotetext{
${ }^{4}$ Metaph., E, 1, 1026a30-31.

5 Heidegger, M. «Die ontotheologische Verfassung der Metaphysik», in: Identität und Differenz, Pfullingen, 1957.

6 Brague, R. Aristote et la question du monde, Paris, 1987, p. 110.

7 D.M.II, 1,1 .
} 
Podríamos dudar de ello, si es cierto que la denominación de concepto es extrínseca en relación al objeto, el cual existe en sí, indiferente a que yo lo conciba (o no lo conciba); si es igualmente cierto que el concepto objetivo puede ser confuso o ficticio incluso cuando el concepto formal que yo tengo de él es verdadero y positivo: esto es lo que ocurre, por ejemplo, en el caso de la quimera. De esta manera, podría ocurrir que tuviéramos un concepto formal del ser al cual no correspondería ningún concepto objetivo. Pero esta posibilidad está descartada: «si el concepto formal es uno, es necesario que el concepto objetivo sea igualmente uno.» 8

Hay aquí una dificultad. ¿Qué es lo que autoriza a Suárez concluir, en general, a partir de la unidad del concepto formal la unidad del concepto objetivo, del hecho de la existencia de uno a la existencia del otro? Si es verdad que la unidad es lo propio del concepto y, de ese modo, si se da la unidad ¿se prueba la existencia del concepto correspondiente? Estaría tentado de seguir la interpretación de Jean-Luc Marion ${ }^{9}$, para quien la necesidad de esta conclusión, afirmada a propósito del concepto de ser, no vale precisamente más que en este caso, por causa de que el ser no tiene otra objetividad más que la el hecho de ser pensado, representado, dicho de otra forma, de dar lugar a un concepto formal. La objetividad del ser no necesita de otra prueba más que la de su representabilidad puesto que ella es la representabilidad en sí misma.

De hecho, la prueba que aporta Suárez de la unidad del concepto de ser tiene todas las apariencias de la circularidad. Todos los entes reales constan verdaderamente entre ellos de una cierta similitud y de una cierta conveniencia en su razón de ser; se puede, entonces, concebirlos y representarlos bajo esta noción distinta por la cual ellos convienen entre sí. Pero, recíprocamente, puesto que podemos concebirlos bajo una razón distinta que funda la conveniencia entre ellos, (o dicho de otro modo: puesto que hay un concepto formal de ser), hay un concepto objetivo: «la unidad del concepto objetivo no consiste en una unidad real y numérica, sino en una unidad formal o fundamental, que no es otra cosa que la conveniencia o semejanza antes propuesta» 10

El principal argumento en favor de la unidad del concepto de ser es, pues, la experiencia del pensamiento. Desde este punto de vista, la posición de Suárez no parece fundamentalmente distinta a la de Duns Escoto, que escribe: «Experimur in nobis ipsis quod possumus concipere ens»11. Hay una certitudo en cuanto a la realidad de este concepto. La experiencia, sin embargo, es diferente en el uno y en el

\footnotetext{
${ }^{8}$ D.M. II, 2,3. [Nota traductor: Todas las traducciones de la obra de Suárez provendrán de aquí en adelante de la siguiente edición: Suárez, F. Disputaciones Metafísicas, Rábade Romeo, S., Caballero Sánchez, S. y Puigcerver Zanón, A., vol. I, Biblioteca Hispánica de Filosofía, Ed. Gredos, Madrid 1960-1967].

9 Marion, J.-L. Sur le prisme métaphysique de Descartes, Paris, 1986, notablemente p. 54.

10 D.M. II, 2,14. (Ibíd., p. 384).
} 
otro. En Duns Escoto se trata de la experiencia de un ens commune anterior e indiferente a toda determinación (por ejemplo, in se y in alio, infinitum y finitum). En Suárez se trata principalmente de un sentimiento de conveniencia, reconocido a posteriori, que liga entre ellos, a pesar de sus diferencias, realidades heterogéneas.

La experiencia suareciana del ser es una experiencia que vuelve caduca y obsoleta la afirmación de la analogía, al menos la de una analogía rigurosa y restrictiva tal como la entendía Cayetano, que no autorizaba entre los términos análogos más que una unidad de denominación extrínseca. Concretamente: ¿Hay conveniencia entre la sustancia y el accidente, no obstante el abismo que los separa? La respuesta de Suárez es: Sí, pues el intelecto descubre una conveniencia más grande entre la substancia y el accidente que entre la substancia y el no-ente o nada. ${ }^{12}$ ¿Hay conveniencia entre Dios y la criatura? La respuesta de Suárez es: Sí, pues percibimos una conveniencia más grande entre Dios y la criatura, que entre Dios y la nada. La trascendencia de Dios no es tal que la criatura en relación a Dios no sea más que una nada. La criatura es una "huella de Dios" (vestigium Dei)13. He ahí por qué podemos investigar el ser de Dios a partir del ser de la criatura. He ahí por qué también concebimos los atributos comunes a todos los entes, como la bondad, la perfección, la potencia, la comunicación o la comunicabilidad, etc. Estamos aquí en las antípodas de la teología negativa.

Admitiendo que la conveniencia que existe entre los entes no es tan perfecta como la que existe al interior de un género determinado de entes, Suárez se inclina claramente hacia la univocidad. Si por "defender la analogía" se necesitaba negar la unidad del concepto de ser, «habría de negarse antes la analogía, que es incierta, que la unidad del concepto, que parece demostrarse con argumentos ciertos».14 La analogía no puede ser salvada más que si, al contrario que Cayetano, ella no es interpretada como una simple unidad de denominación extrínseca, sino que es interpretada en el sentido platónico de una participación desigual a una razón común, aunque intrínseca cada vez.

¿Cuál es, pues, esta razón común del ser en tanto que tal? Hemos visto que el ser surge negativamente sobre el fondo de la nada. Es ente lo que se opone a lo noente. Pero es necesario decir más: hay una manera uniforme de no ser nada; hay una razón común de lo que no es un no-ente. En la determinación conceptual de esta razón común, Suárez se enfrenta a la ambigüedad del participio ens, que se dice de las cosas existentes, pero igualmente de la quididad o de la esencia de las cosas de las que nos preguntamos si existen. Ens responde doblemente a la cuestión quid est (ti esti) y a la cuestión an sit (ei esti). Se podría disociar enteramente estos dos sen-

\footnotetext{
11 Duns Scotus, Quaestiones in metaphysicam, 1, IV, q. 1, n. 6.

12 D.M. II, 2, 14.

13 Ibid.

14 D.M., II, 2, 36.
} 
tidos y decir con Avicena que la existencia es un accidente de la esencia, la cual es, en tanto que tal, indiferente al existir. Suárez rechaza esta disociación. Ciertamente, el ens en tanto que participio, en el sentido gramatical del término, participa del acto de existir, del actus essendi. Mas el ser en tanto que nombre, ens ut nomen, es decir, el participio sustantivado, adquiere una significación propia, que no necesita referencia a la existencia actualmente ejercida (esta es la función del verbo con su cosignficación temporal), sino que refiere solamente a la posibilidad de existir, de poder existir. La cuestión pasa a ser, entonces: ¿qué hay de común a estos dos sentidos de ser: existir y poder existir?

Podría pensarse en primera instancia que es el existir. Mas el existir tiene menos extensión que el poder existir; el existir no es más que una especie del poder existir. El ens ut nomen es pues más fundamental que el ens ut participium, ya que para participar del esse actual todo ente debe realizar de entrada el requisito de la entidad en general, que es el poder existir. Esta es la inversión suareciana, que sustituye la primacía del existir, del actus essendi, al que parecía estar ordenado el ente participado, por la primacía del poder existir, que define el ens nominal, es decir la cosa, la res.

Finalmente de ahí proviene la respuesta a la cuestión sobre la unidad de la razón de ser: « (...) ratio consistit in hoc, quod sit habens essentiam realem, id est non fictam nec chymaericam, sed veram et aptam ad realiter existendum.» 15

Ahora bien, lo que puede existir es lo que no implica contradicción, «lo que no repugna a la existencia» como dirá Wolff en la estela de Suárez ${ }^{16}$, pues esta solo puede ser producida por Dios, precisa Suárez ${ }^{17}$. El acto creador de Dios, el paso de la esencia real a la esencia actual, está subordinado a la realidad de la esencia, es decir, a su pensabilidad por el entendimiento de Dios; pero también por todo entendimiento, si es verdad que la realitas no puede ser ya definida por referencia a la existencia que la actualiza sino por oposición a la nada (nihil), es decir, a lo impensable. La realidad en el sentido de la determinación esencial, tal como es representada, basta para fundar la entidad del ente o, lo que es lo mismo para Suárez, de la res.

Así desde Suárez se pone en marcha el arsenal argumentativo que permitirá deconstruir el argumento ontológico, argumento central de la onto-teología, según el cual la esencia infinita o incluso el ens realissimus existe en virtud de su misma perfección, ya que nada viene a limitar su aptitud a existir. Para Suárez, como más tarde para Kant, la realitas, que se opone a la nada, pero no incluye nada más que

15 D.M., II, 4, 5 «su razón [la de ente; nota traductor] consiste en ser algo que tiene esencia real, es decir, no ficticia ni quimérica, sino verdadera y apta para existir realmente.».

16 Wolff, C. Ontologia, 134. [Nota traductor: la cita completa es: «Ens dicitur, quod existere potest, consequenter cui existentia non repugnant». La Ontologia de Wolff se encuentra disponible en: http://reader.digitale-sammlungen.de/resolve/display/bsb10008292.html]

17 D.M., II, 4, 7. 
su pensabilidad, no implica de ninguna manera la existencia, la cual no incrementa en nada la "realidad" de la cosa. Según el famoso ejemplo de Kant, que es suareciano hasta en la terminología, no hay nada más en el concepto de cien taleros existentes (wirklich, actuales) que el concepto de cien taleros posibles, puesto que estos tienen la misma realidad (Realität, realitas), sean existentes o no. ${ }^{18}$

$* * *$

La tesis de Suárez sobre el ser tendrá consecuencias incalculables para la historia ulterior de la metafísica.

La primera, indicada por el mismo Suárez en la primera Disputatio, es la emancipación de la ontología respecto de la teología, y, por tanto, la ruptura de la articulación onto-teológica de la metafísica. Esta ruptura se produce ya desde la primera Disputatio, que se pregunta cuál es el objeto de la filosofía primera o metafísica. Tradicionalmente, y ya en Aristóteles, se dan dos: el ser en tanto que ser y el género más eminente de lo ente, Dios. De un lado, ens commune, ens abstractissimum, ratio abstractissima entis; del otro ens primum, ens summum, substantia prima. La mayor parte de los metafísicos anteriores se esforzaban por unificar estas dos tareas de la metafísica estableciendo, según la sugerencia del propio Aristóteles, una relación de causalidad entre la una y la otra. Así Santo Tomás, para quien el ente supremo es la causa del ente en su totalidad: «Deus est causa universalis totius esse» 19 o también «Deus est propie causa ipsius esse universalis in rebus omni$b u s »^{20}$, lo que es la exacta recuperación del katholou oti proton de Aristóteles. Pero a esta concepción que haría de la metafísica una teología de la cual dependería una ontología general, Suárez objeta de entrada que Dios se encontraría excluido de la metafísica, si él fuera la causa extrínseca del ente en su totalidad. En realidad, Dios forma parte del objeto de la metafísica en la medida en que él mismo es un ente. Por otra parte, la metafísica estaría incompleta si solo tratara del ser de Dios; de hecho, trata también del ser de las criaturas. El hecho que Dios no sea más substancia o

\footnotetext{
18 Se ve aquí que no se puede comprender el argumento kantiano (KrV B 627/ A 599), si como hacen la mayoría de los traductores de la Crítica de la Razón Pura en lenguas romances, se traduce "wirklich" por "real". La realidad (Realität, realitas) es una categoría de la cualidad; su contrario es la negación. La existencia (Wirklichkeit, actualitas) es una categoría de la modalidad, su contrario es la posibilidad. Para Kant, como para Suárez, la oposición posibilidad - existencia es segunda por relación al acto determinante del pensamiento que funda la realidad. Kant, como Suárez, quiere decir que la existencia no añade nada al concepto, ya que aquel está enteramente constituido - y arrebatado de la nada - por su "realidad" (realitas). Cf. P. Aubenque, «La thèse de Kant sur l'être et ses origines aristotéliciennes», in: L'art des confins. Mélanges offerts à M. de Gandillac, Paris, 1985, pp. 513-553.

19 S. Theol. I' ${ }^{\circ}$, q. 45, a.2, ca.

20 Ibid. I $^{\circ}$, q.105, a.5, ca.
} 
esencia no impide que la metafísica deba estudiar las diez categorías, de las cuales la substancia no es más que la primera.

La conclusión es que Dios no es el objeto adecuado de la metafísica. Dios es solamente, por así decir, el objeto principal (praecipuum, principale). El objeto adecuado de la metafísica es el ente en cuanto tal, es decir, el ente común a Dios y a las criaturas, común a la substancia y a las otras categorías. ${ }^{21}$ «Dios cae bajo el objeto de esta ciencia (Deus cadit sub obiectum huius scientiae)»22. La consecuencia epistemológica que de ahí se extrae es que la ontología precede a la teología en el orden del conocer: «Sin embargo, tal conocimiento de Dios exacto y demostrativo no puede obtenerse a través de la teología natural si no se conocen primero las razones comunes de ente, sustancia, causa y demás, ya que Dios no lo conocemos nosotros más que por sus efectos y a través de razones comunes». ${ }^{23}$ Es sobre estas "razones comunes", a veces llamadas "transcendentales" por Suárez (en el sentido de "transcendentales" de la escolástica), sobre estas "primalitates entis", de lo que tratará la ciencia del ser. Esta ciencia, convertida así en autónoma, puesto que es anterior y previa a la teología, bien merecerá a partir de entonces un nombre que le sea propio: este será el nombre de "ontología", que aparecerá poco después por primera vez en la escuela de Suárez o bajo su influencia. ${ }^{24}$ La teología conserva su eminencia, mas ella pierde su prioridad epistemológica, su aprioridad; estaríamos entonces tentados de decir que se recupera una expresión, la de a priori, que, junto a la de "transcendental", comienza a aparecer en los textos de Suárez. El a priori ontológico suplanta a partir de ahora la trascendencia óntica del primum de la metafísica anterior.

Si esta transformación ha podido producirse es porque el ser se ha reducido a posibilidad, (definida esta por su pensabilidad), es decir lo que Leibniz llamará cognibilitas. El ser en tanto que razón formal a priori de todo lo que pensamos como posible y, por lo mismo como real, es subyacente a todas nuestras representaciones, incluso a nuestra representación de lo divino. Como el ser es lo pensable y el pensamiento es pensamiento del ser, no estamos lejos de la tesis según la cual el «yo pienso» es el vehículo de nuestras representaciones y de esta otra tesis, ligada a la

21 «(...) el concepto formal de ser (...) no significa expresamente ni la sustancia, ni el accidente, ni a Dios, ni a la criatura, sino que significa todas esas cosas como si fueran una sola, a saber, en cuanto son de algún modo semejantes entre sí y convienen en ser (conveniunt in essendo)» D.M., II, 2,8.

22 D.M., I, 1, 19.

23 D.M., I, 5, 15.

${ }^{24}$ El término ontología ( en griego!) se encuentra por primera vez en el Lexicon philosophicum de Glocenius, Francfort Main, 1613, p. 16, y en latín en la $3^{\circ}$ edición (Amsterdam, 1664) de los Elementa philosophiae sive Ontosophiae de Johannes Clauberg (1 ${ }^{\circ}$ ed. Groningen, 1647). [Nota del traductor: Se ha hecho continuado investigando sobre el origen de la palabra Ontología. Cf. Esposito, C. Lammana, M. Sulla prima occorrenza del termine «Ontologia». Una nota bibliográfica in: Quaestio: annuario di storia della metafisica, Turnhout, Belgium: Brepols, 2011, No 11, págs. 255-288]. 
precedente, según la cual las condiciones de posibilidad de la experiencia son las condiciones de posibilidad del objeto de la experiencia.

La historia de la ontología, a pesar de las inflexiones que una visión parcial permite distinguir, está marcada por una subterránea circularidad. Más allá del parricidio platónico, concesión a un pensamiento de la alteridad, más allá de la ontologificación aristotélica del movimiento y la subordinación tomista del ente en su totalidad a la contingencia de la donación de la existencia por Dios, Suárez retoma el sentido profundo de la tesis parmenídea de la identidad del ser y del pensar. El anuncia la onto-logía hegeliana, que hace de Dios mismo, Ens realissimum, "la idea absoluta", "la verdad que se sabe a sí misma", dicho de otra manera, la reduplicación y la exacerbación tautológica de la pensabilidad del ente.

Por suerte, Suárez no llega tan lejos. Pero con él se pone en marcha el fundamento conceptual de lo que será la metafísica de la subjetividad y la filosofía trascendental de los modernos; quien prolonga, subvirtiéndola, la metafísica griega del ser. 